\title{
Erinnerung an Günter Graf
}

Günter Graf, von dessen Tod am 29. Oktober 2007 wir in Heft 4/2007 unserer Zeitschrift berichtet haben, war der Gründer und von 1952 bis 1994 Leiter der Bischöflichen Pressestelle in Münster und als solcher u.a. Chefredakteur des Nachrichtendienstes Münster (ndm). So nüchtern, sachlich und bescheiden wie dieser Einleitungssatz pflegte er sich zu geben. In der Zeit, als Heinrich Tenhumberg erst Weihbischof und dann Bischof von Münster war, gab es Leute, die ihn eine graue Eminenz der katholischen Publizistik in Deutschland nannten. Dies hätte er entschieden von sich gewiesen, und er war es auch nicht wirklich, jedenfalls nicht im Sinne des Strippenziehers. Aber er konnte durchaus ein Stratege sein, wenn dies geboten schien, dabei ein stets loyaler Diener seines Herrn, und das war in der Regel der jeweilige Bischof von Münster.

Als ich Günter Graf in meinem ersten Semester an der Universität Münster (Sommer 1954) kennen lernte, wusste ich noch nicht, was ein typischer Münsteraner war, aber ich glaubte zu wissen, dass er ein solcher Typ war. Erst viel später erfuhr ich, dass ich mich geirrt hatte. Er wurde in Brüggen im Erftkreis geboren (18. Juni 1928), war also eigentlich Rheinländer und kam erst 1939 nach Münster, von wo er auch nicht wegging, als er von 1976 bis 1987 das Referat Presse und Verlagswesen der Zentralstelle Medien der Deutschen Bischofskonferenz leitete und anschließend Chef der Zentralstelle werden sollte. "Die endgültige Übernahme dieses Amtes kam nicht zustande, weil ich in Münster bleiben wollte."

Wie er zur katholischen Publizistik kam, beschrieb er 2002 in einem Vortrag, den wir, auch weil es sich um eine Probe seines lapidaren Stils und Habitus' handelt, kurz zitieren:

„Weitere Stationen: 1946 Abitur in Tecklenburg. Vor Beginn des Studiums obligatorischer Einsatz beim Wiederaufbau der Uni Münster. [...] In den Semesterferien Volontariat bei den 'Westfälischen Nachrichten' und der ,Münsterschen Zeitung' mit einer Abschlußbescheinigung ,Redakteur'. 1952 Promotion in Publizistik, Englisch und Kunstgeschichte. (Als ich anfing zu studieren, wollte ich Lehrer mit den Fächern Latein, Englisch und Deutsch werden. Aber nach zwei Semestern bin ich umgestiegen.) Im selben Jahr Gründung und Leitung der Bischöflichen Presse- 
stelle in Münster, der ersten in einem Bistum überhaupt, dank der Initiative eines Bauernsohns im Kreis Ahaus, der Heinrich Tenhumberg hieß, damals Domvikar war, später Bischof wurde und mit dem mich eine solide Freundschaft verbunden hat."

In den frühen Jahren der Zusammenarbeit mit Tenhumberg war Graf bemüht, Studienanfänger der Publizistik zur Mitarbeit an seinen verschiedenen Vorhaben zu gewinnen. Dafür gründete er einen Club junger Publizisten. Er öffnete Wege, schuf Kontakte, ermöglichte auch blutigen Anfängern journalistische Erprobung. Zu Münsters Tageszeitungen fand ich über ihn Zugang, und meine ersten Honorare verdiente ich mit kurzen Meldungen für seinen ndm. Fünf Mark für zehn Zeilen, und das drei oder vier Mal im Monat, bedeuteten eine erhebliche Aufbesserung meines kargen Monatswechsels. Die zehn Zeilen aber - das lernte ich damals - mussten passen: Kein wichtiges Faktum zu wenig, aber kein Wort zu viel. Grafs Neigung zum Nachrichtenstil zeigte sich schon in seiner publizistikwissenschaftlichen Dissertation von 1952: "Der ,Spectator" von Addison und Steele“; weniger als 150 Seiten, wenn ich mich recht erinnere, und somit ein Zeichen der Hoffnung für Jungpublizisten, die damals nicht anders als mit einer Dissertation ihr Studium abschließen konnten.

Der ndm wurde wegen seiner soliden Nachrichtengebung von Journalistenkollegen geschätzt und von der Katholischen Nachrichtenagentur als Regionalausgabe adoptiert. Er begründete das Ansehen der bislang unbekannten, bald aber von allen deutschen Diözesen übernommenen Innovation "Bischöfliche Pressestelle“. Auch nach seiner Pensionierung konnte Günther Graf das Nachrichtenschreiben nicht lassen. Schon seit 1988 redigierte er die zehnmal pro Jahr erscheinenden "Informationen“ der Gesellschaft Katholischer Publizisten Deutschlands, deren Vorstand er viele Jahre hindurch angehörte. Die "Informationen“ entwickelten sich je länger je mehr zu einem typisch Grafschen Produkt: inhaltsreich, interessant, solide, von keinem Zeitgeist angekränkelt.

Großes Engagement verlangten ihm (ab 1965) die Jahre der Vorbereitung, Gründung und schließlich des Endes der katholischen Wochenzeitung "Publik" (1968-1971) ab. In dieser Phase wurde Bischof Tenhumberg, gestützt auf Grafs Zuarbeit, zum entschiedenen Verfechter der "Publik"-Idee und - innerhalb der Deutschen Bischofskonferenz - zum Vorkämpfer der Wiederbelebung des bereits eingestellten Wochenblatts.

Darüber hat Günter Graf vor gar nicht langer Zeit in "Communicatio Socialis" berichtet (Heft 3/2004). Der Auslöser dieses Beitrags war 
eine missratene Frankfurter Dissertation über „Publik", bei deren Besprechung er - immer noch relativ unterkühlt - zu scharfem Ton findet. Günter Graf hat nicht oft für unsere Zeitschrift geschrieben, aber er war offenbar einer ihrer aufmerksamsten Leser. Das zeigte sich in spontanen Anrufen, teils kritisch, teils lobend, teils Diskussion anbietend und auslösend. Das Echo davon fand sich wieder und wieder auch in den "Informationen". In der Art, wie er sein Leben lang den Dienst an der katholischen Publizistik gesehen und betrieben hat, waren wir einig im Geiste. Wir haben ihm zu danken für gemeinsames Nachdenken, Handeln und jahrzehntelange Freundschaft. 